\title{
Workplace-integrated assistance systems conducive to learning designed for production
}

Tina Haase, Wilhelm Termath; Michael Dick, Dirk Berndt, Michael Schenk

1. Digital Assistive Technologies

Digital cognitive assistance systems already support the employee in many areas of work (Niehaus 2017). In the field of maintenance, the employee requests status data of complex technical systems, opens the latest maintenance documents for a malfunctioning component in the work situation and receives information about the machine and the colleague who conducted the last maintenance (Keller/Haase 2019).

In the commissioning department, the warehouse employees are guided using data glasses and pick-to-light.

In manual assembly, assistance systems are used to support employees in the assembly of increasingly diversified products. Step-by-step instructions on a display installed close to the workstation are currently the most common (Haase et al. 2020).

The very heterogeneous applications show the diversity of the required assistance contents as well as the different devices for their display. Various challenges accompany the use of digital assistance systems:

\section{1) Ironies of Automation}

Because of the increasing interconnection, automation, and digitization of machines and systems, the human task in the work system is changing more and more towards a monitoring and controlling function. The troubleshooting of minor malfunctions, from which employees could gain experience in the past, are hardly available today. Nevertheless, it is necessary and expected of the employee to react quickly, efficiently, and correctly to the failure situation. The dilemma of the "Ironies of automation" (Bainbridge 1983) makes clear that the support, on the one hand, leads to relief for the employee, but on the other hand, generates the need for new learning opportunities. 


\section{2) Dequalification}

Particularly in standardized processes and activities, the use of digital assistance systems is associated with the risk of employee dequalification. The technical system reliably provides necessary information for processing the next step and the employee executes it. It is often not necessary to understand why a work step must be conducted in a certain way or which alternative procedures would be possible. In this scenario, the employee has taken over the executing role in the cooperation between human and machine. There are operational scenarios in which this scenario has its justification, e.g. in the case of high employee turnover or the case of vacation replacements. To enable the employee to safely act in changing and complex work systems and to be able to generate new problem solutions from existing experiences, a holistic work design is required that prevents dequalification.

In this article, the authors consider assistive technologies for manual assembly processes and base the design of these systems on a fundamental understanding of the cooperation between humans and machines, which still assigns decisions and responsibility to humans. The assistance system is understood as a capability-enhancing system. It is designed in such a way that it enables learning in the process of work, expands the scope of action of the employees, adapts to their needs and the work situation, and contributes to quality assurance of the components to be assembled.

In this paper, the authors present a methodological approach for designing assistance systems conducive to learning. The theoretical framework is based on the activity system and the concept of expansive learning. From these, the authors develop the learning activity system. In section 3, the application and further development of this theoretical framework are presented based on an operational use case of mechatronics reprocessing. It includes a systematic approach to technology selection and design, which serves companies as a practical guide in the design of assistance systems.

In addition, dimensions of conduciveness to learning are developed and linked to the activity system approach. This integrated model provides requirements for the design of an assistance system that is conducive to learning. Finally, the authors show specific requirements and measures for a participatory design and implementation process.

\section{From the activity system to the learning activity system}

\subsection{Activity system and expansive learning theory}

The realization of the claim of a holistic, participatory work design, also in the design of the assistance system, requires a correspondingly broad theoretical 

production

framework to connect the individual learning of the working person with the organization's framework and its development dynamics.

The activity theory (Kölbl 2010) developed from works of the School of Cultural History (Leontjew 1979) distinguishes between activities, actions, and operations. In this understanding, activities in their representational character function as a connection between the individual and the organization or society. They represent material or ideal motive for the individual. The action, on the other hand, is a work action related to a specific objective, which is realized by executing individual operations.

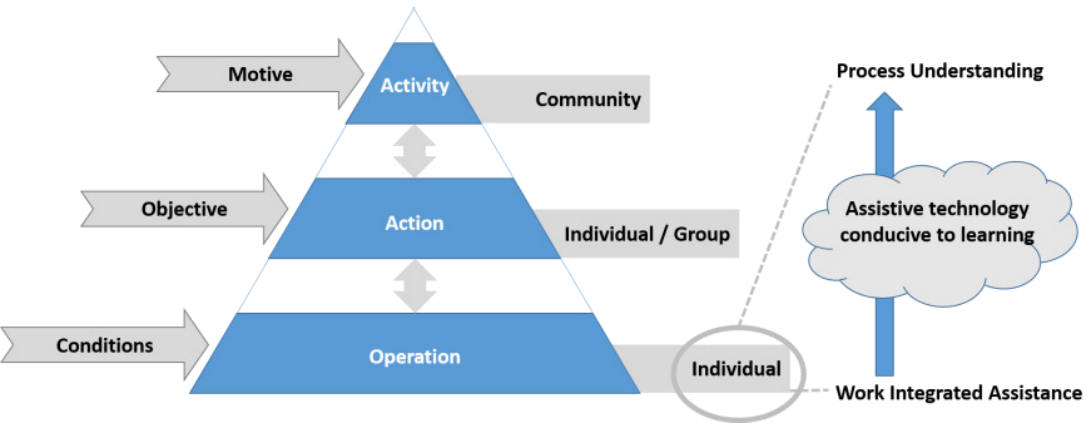

Figure 1: Activity system and assignment of the assistance system; following (Leontjew 1979)

The relevance of this distinction for the design of assistance systems is, first of all, to enable the working persons to relate to the object of their work as a meaningful and thus motivating element. In the automotive industry, for example, the screwing of a bolt into a certain base plate with a defined torque is an operation, the assembly of a mechatronic system is the overall objective, and the production of a car is the activity.

The visualization of Yrjö Engeström (Engeström 1987) illustrates the embedding of the subjects in the dimensions of the environment or organization as the basic structure of an activity system. (see figure 1).

The upper triangle of a subject, tool, and object stands for the individual who processes objects with the help of tools. The elements rules, community, and division of labor represent the organizational or social reference of an individual's actions. The set of these elements forms the activity system. For the activities of employees in an industrial company, the elements of the activity system can be described as follows:

The Subject is the acting person, e.g. as a worker on the shop floor, development engineer, or head of department. 


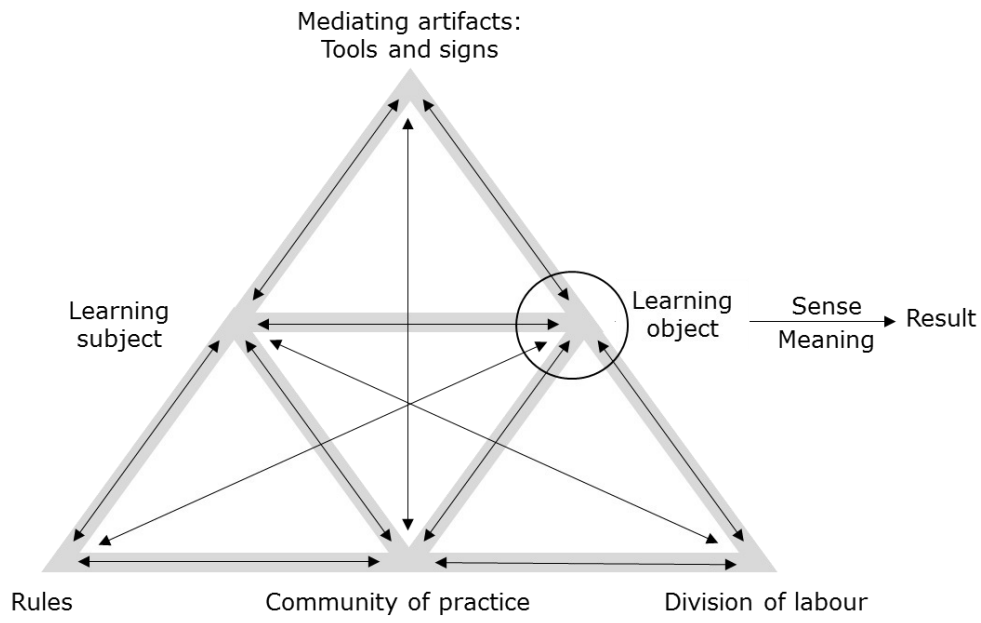

The Object is the product in its entirety or parts, e.g. a car or a machine, but also the mission and the company's self-image.

Tools are on the one hand material tools such as machines, drills, or electrical diagrams, but on the other hand also methods, procedures, or expertise.

Figure 2: Structure of a human activity system

(Engeström 1987, cited in Engeström 2008)

Rules are both explicit regulations and procedural guidelines as well as implicit acceptance of a certain behavior or taboos.

Community refers to teams, shifts or departments.

The division of labor describes the cooperation of the different professions or departments in the value chain.

After empirical studies in institutions of medical care in the Helsinki area, among others, Engeström (2008) developed his research as an extension of the activitytheoretical basic model for understanding and integrating dimensions such as "... dialogue, multiperspective and networks..." (ibid. p. 64). The complexity of organizations can therefore only be grasped by analyzing several inter-active systems of activity, which include at least one common "collectively significant object" (ibid. p. 65).

The behavior of the individuals in this activity system or the work in a company that is understood as several interactive activity systems is therefore always characterized by contradictions between individual elements of the system or between several activity systems of the company. The perception of such contradictions - 

production

e.g. the change of instructions or the restructuring of departments - requires from the individuals a corresponding adjustment of their behavior or way of working. In the understanding of the activity theory, these contradictions are important impulses for learning processes.

In the theoretical foundation of learning, Engeström refers to the work of Gregor Bateson (1983) with the distinction of three stages of learning. In the first stage the correct answering of questions or the "correction of errors in the selection within a set of alternatives" (ibid. p. 379), e.g. the correct handling of a tool, dominates. By learning II Bateson means an extension of learning I in the sense of a corrective change of the set of alternatives, possibly the idea for the use of another tool. Learning III finally means "... a corrective change in the system of sets of alternatives among which the choice is made" (ibid. p. 379).

Resulting contradictions, e.g. about the cost-effectiveness of a change in the use of tools or technology, can lead to fundamental changes in processes. Even if employees on the shop floor do not make these decisions themselves, it is important that they can experience their actions as a plausible and meaningful contribution to value creation.

\subsection{Development of the learning activity system}

The increasing integration of information technology into work systems motivated teams of researchers from the universities of Magdeburg, Bremen, and Karlsruhe to submit a research proposal in 2005 to explore the potential of virtual reality technologies for supporting individual and organizational learning in the work process (OLIVA 2007). In the first research period, individual learning processes were supposed to be supported by virtual learning media, in the second period this was extended to include cooperative and organizational learning. For the third phase, the vision of a "learning space virtual working world" was developed, in which individuals work and learn in distributed work systems in different domains and at various locations.

Engeström's activity system provided an analytical framework for conceptualizing both individual learning processes in the upper triad and their organizational embedding through the inclusion of the entire activity system (see above).

On this basis, Michael Dick developed the construct of the "learning activity system[s] as a unity of interrelated elements of work activity" (Dick 2007).

These perspectives provide the scientific frame of reference for designing an assistance system that is conducive to learning. 


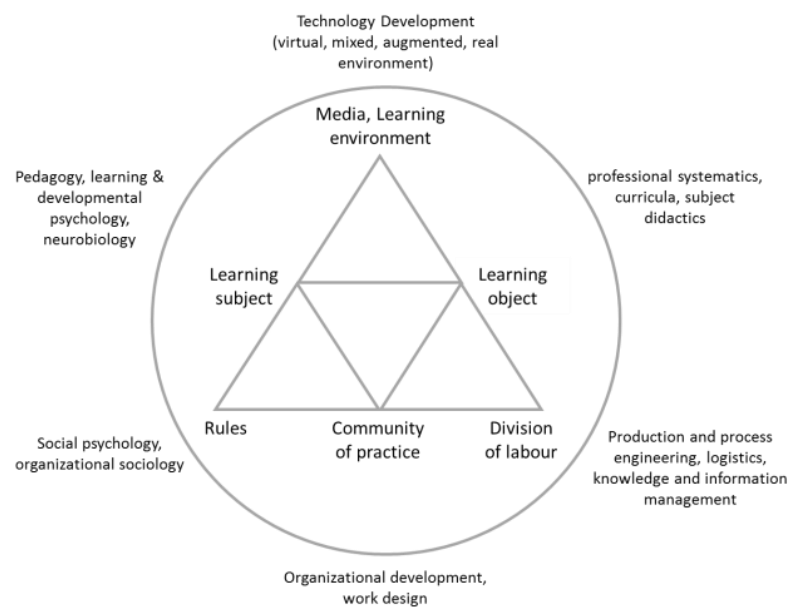

Figure 3: The learning activity system and the main scientific perspectives; following (Dick 2007)

\section{Derivations for the design and implementation process}

From the considerations of the activity system, expansive learning, and the derivation of the learning activity system, practical derivations for the design and implementation process of assistive technology systems conducive to learning that are integrated into the workplace are developed in the following. The first important influencing factors, which determine the later technology selection and design, are determined. For this purpose, different methods of work and requirements analysis are used. Then, concrete dimensions of conduciveness to learning are introduced and linked to the concept of the activity system. Sustainable use and acceptance of the developed solution are supported by a participative implementation and design process. In conclusion, important findings of this process from practical implementation are presented.

\subsection{Parameters that influence the effectiveness of the assistance system}

In the further development of the often technology-centered development processes, the effective use of assistance systems requires the consideration of multiple influencing factors.

The employee as a direct user of the system should be considered in his individuality to meet individual requirements and needs. These are, for example, the age, the level of competence and experience in performing the activity, as well as the motivation to learn, which can be derived from the personal motive (see figure 4). 
Workplace-integrated assistance systems conductive to learning designed for production

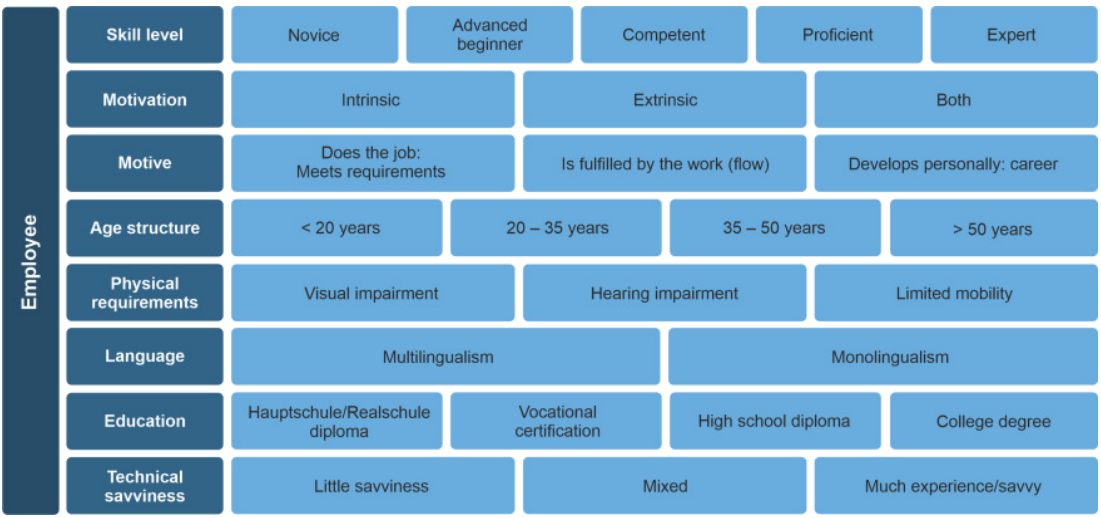

Figure 4: Employee dimension

The learning object includes the activity, its embedding in the overall process, and knowledge about the object that is the subject of the activity. Here, relevant content should be identified that supports the identification of the learner with the product and the activity and thus contributes to the creation of meaning.

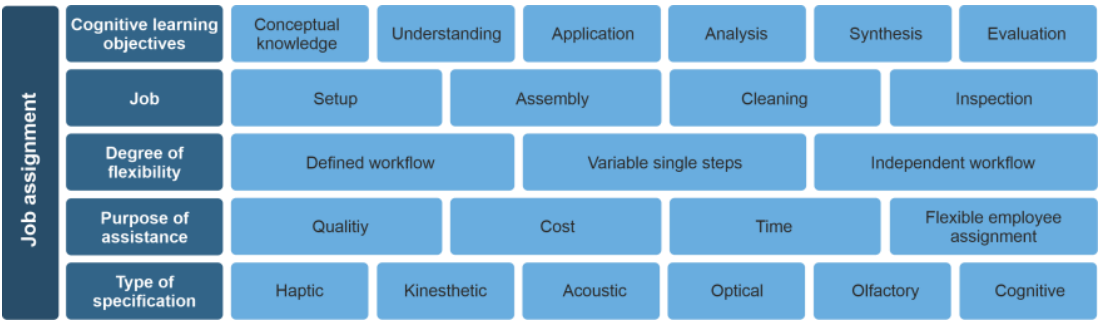

Figure 5: Job assignment dimension

In addition, the learner's involvement in the community of practice should be analyzed to obtain indications of the members of the community of practice and existing possibilities of experience exchange, which must be taken into account when designing exchange processes with the help of the assistance system. This is closely related to the rules, norms, and values that are practiced in the organization and can be seen, for example, in the learning and error culture. Information on these parameters usually requires a well-developed trust relationship and can be mainly collected in informal processes, e.g. through participant observation.

The conditions at the workplace have a significant influence on the selection and design of the technology. Therefore, the identification of factors such as volume, 
brightness, spatial conditions, and existing IT systems is an essential part of the analysis process (see figure 6).
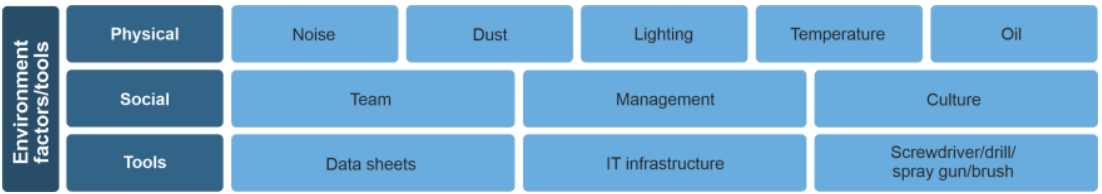

Figure 6: Environmental factors dimension

\subsection{Conducive to learning and work integrated assistance system}

A large number of digital assistance systems developed in recent years to support assembly processes have focused primarily on providing the correct sequence of operations. Examples include pick-to-light systems or desktop displays in the automotive industry. This type of guided and alternative-free specification of correct partial operations without background information and the possibility of exploration tends to restrict learning processes and to dequalify employees (cf. Frieling et al. 2006).

Further development of these systems into assistance systems that promote learning and contribute to development processes among employees requires concrete design criteria (Haase et. al. 2020). They follow the criteria of a working design that is conducive to learning and competence (cf. Franke/ Kleinschmitt 1987; Dehnbostel 1994; Franke 1999) and supplement these with the dimension of system-immanent motivational incentives.
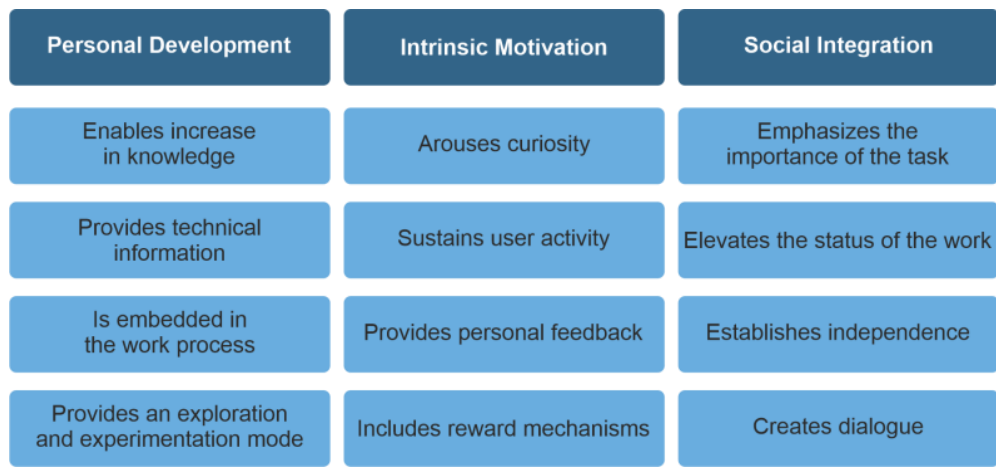

Figure 7: Conduciveness to learning dimensions and derived criteria, following (Fredrich et al. 2021)

The specified criteria (see Fig. 7) are intended to go beyond mere adaptation to a predefined sequence of assembly steps and cover a subjective educational potential. This can consist, for example, of deepening and broadening existing knowledge and thus linking individual goals, or of placing oneself in a collegial 

production

context and participating in the further development of work processes. Making one's contribution to the overall performance visible creates meaning and identity (Wehner et. al. 1996). The assistance system can become the symbol and artifact of a "community of practice" (Wenger 1998). Mechanisms that arouse curiosity and sustain engagement with the object of learning can support these processes.

\subsection{Integration of activity system and design conducive to learning}

Concerning the learning activity system, these criteria of conduciveness to learning can be related in summary to the three levels of learning (see Section 2.1).

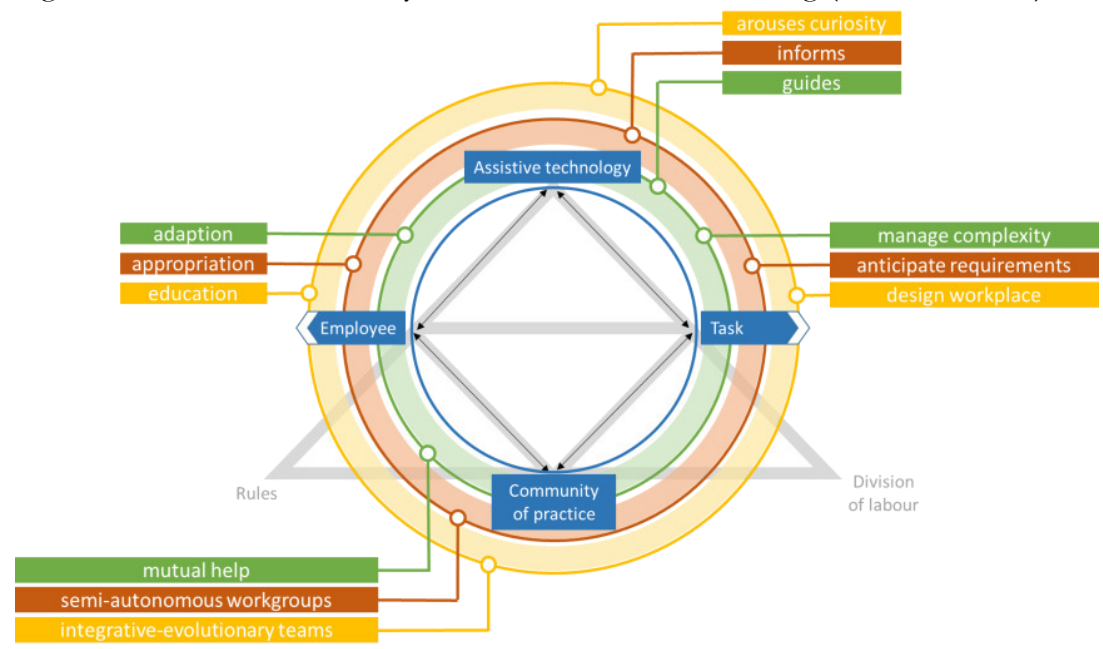

Figure 8: Conduciveness to learning in the activity system

At the Learning I level (operation; inner circle), the assistance system supports the execution of an operation and thus has primarily an instructional function.

A system that enables learning II (action; middle circle) contains further assistance content that supports understanding and thus enables transfer to similar actions. It is oriented to the objective.

Learning III (activity; outer circle) does not take place in the assembly directly by the employees themselves, but more on the management level. The motives of the group and the associated operational goals should also be known to the assembly employees to be able to relate their actions to these goals. In mechatronics preparation, for example, an explanatory video has been created that clarifies the contribution of mechatronics preparation as a contribution to the organization's sustainability strategy. It thus serves to motivate the employees and give them a sense of purpose. 


\subsection{Participatory implementation process}

The effectiveness of an assistance system is significantly determined by the acceptance of the system by the employees. If it is achieved that the system becomes a self-evident "tool" of the employees, constant use and thus also an up-to-dateness of the contents can be enabled.

The creation of acceptance, combined with sustainable use and a shared vision of the effectiveness of the system, requires a negotiation process between professional, work design, and technological perspectives in the early phase of system design (see Fig. 9).

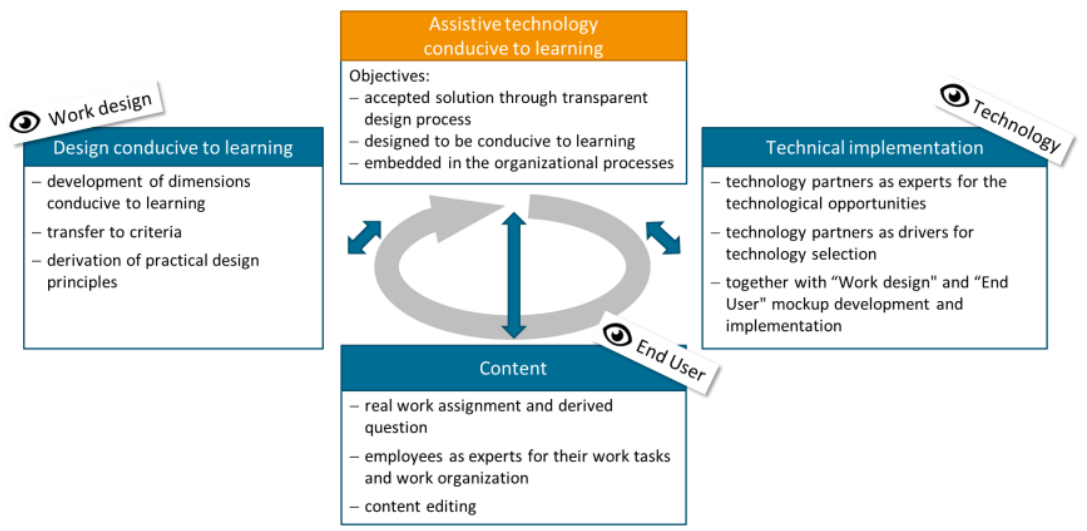

Figure 9: Interdisciplinary negotiation process

In this context, work design as the realization of a didactic concept focuses on the design that is conducive to learning and the embedding of the assistive technology solution in the work organization of the company. The resulting changes must be made visible at an early stage and their effects must be made tangible. The users stand for the validity of the assistance content and the relevance of the task supported by the system. The employees are the experts for their workplace, the organization with its rules, norms, and values and they are part of the community of practice. Designing a digital assistance system also requires a technological perspective and expertise. Technology experts know the technical scope of possibilities, can link the new solution to the existing IT infrastructure, and thus provide the impetus for technology selection. A solution that reflects all perspectives equally requires an awareness of these perspectives on the part of everyone involved and a willingness to make the design decisions in this area of tension together. 

production

\section{Application of the learning activity system in practice}

In the BMBF-funded research project LeARn4Assembly (FKZ: 01PV18007A), assistance systems conducive to learning are designed and implemented. The application of the learning activity system and the process of designing and introducing a new assistance system are described about a scenario of mechatronics assembly at Audi.

Figure 10 uses the example to show four selected references of the learning activity system, which illustrate the interaction of the elements in the system when designing, introducing, and accepting assistance systems:

\section{A) Assistive technology to transfer knowledge about the mechatronics}

Assistive technologies conducive to learning have the potential to provide knowledge about the product to be manufactured beyond support in operating, and thus to integrate the actions of the employee into an overall process. This can include, for example, how the mechatronics works and how it is installed and operates in the car as the higher-level overall product. In this way, the assistance system contributes to making sense of one's activity and to supporting the identification of the employee with the activity, the product, and the overriding motive of the organization (Learning III).

B) Assistive technology for the documentation and provision of experience-based knowledge, e.g. tips and tricks for the handling of the mechatronics

In addition to the instructional provision of assistance content for performing the activity, employees appropriate expert knowledge in their activities, which enables them to act confidently in special situations. Employees usually do not document this experiential knowledge, but exchange it informally in conversations. If such an exchange does not take place, for example, because the opportunity does not present itself or because the person providing the knowledge has reservations about passing it on, the potential of the individual is not passed on to the organization.

The assistance solution tested at Audi will therefore also enable the documentation and use of experiential knowledge in the work process (Haase et al. 2013) (Gerhardt et al. 2020) and thus support an exchange between the employee and colleagues as a community of practice.

C) Assistive technology for the transfer of upstream and downstream processes, e.g. contribution of mechatronic reprocessing to the sustainability of the company

The effects and consequences of one's actions often remain hidden from the employee. For example, the employee is instructed to carry out a process in a certain way, but the reasons are often not communicated. An assistance system that makes these interrelationships transparent to the employee can help to increase the employee's quality awareness because the consequences of a different procedure for 
the subsequent processes are pointed out. The employees in mechatronics processing, for example, play a major role in the organization's sustainability strategy. In the project, an explanatory video was created that makes this connection transparent and comprehensible for the employees.

D) Assistive technology to promote a learning and failure culture, e.g. by reflecting and updating assistant content

The design of assistance systems is also an indication of the learning and error culture that is practiced in the organization. A system that understands itself as an exchange platform between employees, by going beyond formal rules, for example, by documenting their experiences, tips, and tricks there and sharing them with the community of practice, different ways of acting are revealed and thus provide an incentive for exchange, improvement, and learning in the organization. The solution developed in the project at Audi will promote this culture by enabling the technical solution to comment on and evaluate the documented knowledge modules. This is intended to raise awareness of the need for continuous reflection on knowledge and to allow employees to actively participate in shaping it.

\section{Summary and outlook}

Digital assistance systems will increasingly be used to support manual assembly processes. In addition to providing direct support in performing the activity, assistance systems will also make an important contribution to human-centered work in the future. Current research shows that content conducive to learning can contribute to the enhancement of one's activity and thus to a strengthening of employee identification with the company, the product, and the activity. Possible contents, such as the function of the component to be assembled, the costs incurred or one's contribution to the sustainability of the company, enable the employee to classify his activity in the company process. The activity system and the learning activity system derived from it provide a suitable explanatory framework for this.

In addition, the danger of de-qualification can be counteracted and monotonous work sequences can be broken.

This requires a design process that starts from a relevant operational question, follows a systematic process of technology selection, and design and involves the employees in this process.

One target category that has not been addressed in this article and that will gain importance in the future is the adaptability of companies. Assistance systems can be an important building block for strengthening the adaptability of companies, since they rapidly reduce learning times, among other things. The activity system provides the analytical framework and makes clear that contradictions that repeatedly occur in company practice can be understood as opportunities for change and innovation, see Learning III. 


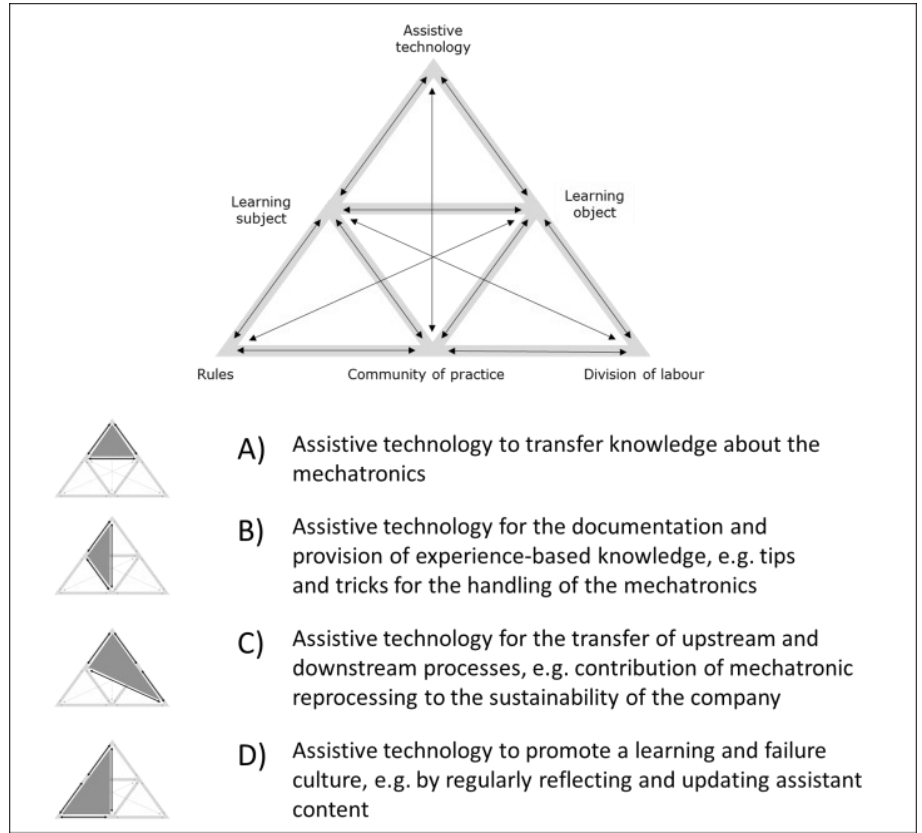

Figure 10: Application of the learning activity system for the design of conducive to learning assistance systems

\section{References}

Bainbridge, L. (1983). Ironies of automation. In Analysis, design and evaluation of man-machine systems (pp. 129-135). Pergamon.

Bateson, G. (1983). Ökologie des Geistes (3. Aufl.). Frankfurt am Main: Suhrkamp.

Dehnbostel, P. (2007). Lernen im Prozess der Arbeit. Münster.

Dick, M. (2007). Das Lerntätigkeitssystem als Rahmenkonzept für die Gestaltung, Implementierung und Nutzung von VR im Arbeitsprozess. In M. Schäper \& M. Schütte (Hrsg.), Kompetenzentwicklung in realen und virtuellen Arbeitssystemen. Bericht zum 53. Kongress der Gesellschaft für Arbeitswissenschaft vom 28. Februar - 2. März 2007 (pp. 29-34). Dortmund: GFA-Press.

Engeström, Y. (2008). Expansives Lernen in der Arbeitswelt. Für eine Neukonzeptionierung der Tätigkeitstheorie. In L. Rosa (Hrsg.), Entwickelnde Arbeitsforschung. Die Tätigkeitstheorie in der Praxis (International cultural-historical human sciences, Bd. 25, 1. Aufl., pp. 61-89). Berlin: lehmanns media.

Engeström, Y. (1987). Learning by expanding: An activity-theoretical approach to developmental research. Helsinki: Orienta-Konsultit. 
Franke, G. (1999). Erfahrung und Kompetenzentwicklung. In: Dehnbostel et. al. (Hrsg.): Erfahrungslernen in der beruflichen Bildung - Beiträge zu einem kontroversen Konzept. Neusäß, pp. 54-70.

Franke, G., Kleinschmitt, M. (1987). Der Lernort Arbeitsplatz. Berlin, Köln.

Fredrich, H., Dick, M., Haase, T., (2021). Zur Passung von Arbeitsanforderungen und digitalen Assistenztechnologien in handwerklichen und industriellen Montageprozessen. In: ARBEIT HUMAINE gestalten. 67. Frühjahrskongress der Gesellschaft für Arbeitswissenschaft 2021. GfAPress.

Frieling, E., Müller, R. F., Bernard, H., \& Bigalk, D. (2006). Lernen durch Arbeit. Waxmann Verlag.

Gerhardt, M., Haase, T., \& Dick, M. (2020, July). Reflections on an Interdisciplinary Approach: Integrating Assistive Technologies and Experience-Based Knowledge in Maintenance. In International Conference on Applied Human Factors and Ergonomics (pp. 787-793). Springer, eCham.

Haase, T., Keller, A., Warschewske, F., Woitag, M., Sauer, S., Berndt, D. (2021): Digital Assembly Assistance Systems: Methods, Technologies and Implementation Strategies. In: Röcker, C., Büttner, S. (Hrsg) (2021): Human-Technology Interaction Shaping the Future of Industrial User Interfaces. Chapter Proposal angenommen; Beitrag in Erstellung.

Haase, T., Radde, J., Keller, A., Berndt, D., \& Dick, M. (2020, July). Integrated Learning and Assistive Systems for Manual Work in Production-Proposal for a Systematic Approach to Technology Selection and Design. In International Conference on Applied Human Factors and Ergonomics (pp. 853-859). Springer, Cham.

Haase, T., Termath, W., \& Martsch, M. (2013, January). How to Save Expert Knowledge for the Organization: Methods for Collecting and Documenting Expert Knowledge Using Virtual Reality based Learning Environments. In VARE (pp. 236-246).

Keller, A., \& Haase, T. (2019). Kognitive Assistenzsysteme in der Prozessindustrie. Ergebnisse eines partizipativen Gestaltungsansatzes. In: Arbeit interdisziplinär analysieren - bewerten - gestalten. 65. Frühjahrskongress der Gesellschaft für Arbeitswissenschaft 2019. GfA-Press.

Kölbl, C. (2010). Kulturhistorische Schule. In G. Mey \& K. Mruck (Hrsg.), Handbuch Qualitative Forschung in der Psychologie (1. Aufl., S. 182-194). Wiesbaden: VS Verlag für Sozialwissenschaften.

Leontjew, A. (1979). Tätigkeit, Bewußtsein, Persönlichkeit (Beiträge zur Psychologie, Bd. 1, 1. Aufl., 1 Band). Berlin: Volk und Wissen Volkseigener Verlag.

Niehaus, J. (2017). Mobile Assistenzsysteme für Industrie 4.0: Gestaltungsoptionen zwischen Autonomie und Kontrolle.

Universität Bremen; Universität Karlsruhe; Universität Magdeburg (2007, 1. August). OLIVA - Organisationales Lernen in virtuellen Arbeitssystemen. Konzeptpapier zur Beantragung eines Sonderforschungsbereiches/Transregios bei der Deutschen Forschungsgemeinschaft (1. Aufl.) (Schenk, M., Spöttl, G., Zülch, G. \& Jenewein, K., Hrsg.). Bremen.

Wehner, T., Clases, C., Endres, E. (1996): Situiertes Lernen und kooperatives Handeln in Praxisgemeinschaften. In: Endres E \& Wehner T(Hrsg.), Zwischenbetriebliche Kooperation. Die Gestaltung von Lieferbeziehungen (S. 71-85). Beltz, Psychologie Verlags Union.

Wenger, E. (1998). Communities of Practice. Learning, Meaning, and Identity. Cambridge University Press. 